\title{
Epidemiology of dystonia, chorea, and athetosis in Al Quseir City (Red Sea Governorate), Egypt
}

\author{
Reda Badry ${ }^{1}$, Mohamed A. Abdelhamed ${ }^{1 *}$, Mohamed A. M. Sayed ${ }^{2}$, Abeer Abd ElHady ${ }^{3}$ and Mohamed Mostafa ${ }^{1}$
}

\begin{abstract}
Background: Movement disorders are common neurological problems, but epidemiological studies are lacking in our locality. Type of movement disorder depends on the site of the lesion and the type of pathologic changes.

Objective: To estimate the prevalence rate of dystonia, chorea, and athetosis, in Al Quseir City (Red Sea Governorate), Egypt.

Methods: This study is a part of a door to door survey of major neurological disorders that was conducted in Al Quseir City, Red Sea Governorate, Egypt, on a sample size of 33,285 subjects. They were screened through 3 neurologists and 15 social workers. Then, each of the three staff members of neurology subjected positive cases to meticulous clinical evaluation separately.

Results: Thirteen cases with dystonia, 7 cases with chorea and 5 cases with athetosis were found with prevalence rates of 39/100,000, 21/100,000, and 15/100,000 respectively.

Conclusion: Prevalence rates of dystonia, chorea, and athetosis in Al Quseir City are higher than those of the worldwide. This may be attributed to some specific environmental factors of this locality.
\end{abstract}

Keywords: Movement disorders, Chorea, Dystonia, Athetosis, Red Sea Governorate, Egypt

\section{Introduction}

The basal ganglia are organized to facilitate and harmonize voluntary movements and to inhibit competing movements that might interfere with the desired movement. Dysfunction of these circuits can lead to movement disorders (MDs) that are characterized by impairment of the voluntary movement, appearance of new involuntary movements, or both [1]. Although there is emerging awareness that movement disorders rank among the most common neurological diseases, the overall burden of these disorders in the general community is not well defined [2]. In spite of the fact that there is a high prevalence of movement disorders in the general community, there is a substantial underrecognition and under-treatment of them [2]. Most of the prevalence data referring to specific movement disorders are hospital-based and provide insight into more disabling

\footnotetext{
*Correspondence: moh78_abdelhamed@yahoo.com

${ }^{1}$ Department of Neurology and Psychiatry, Assiut University, Postbox: 71526, Assiut, Egypt

Full list of author information is available at the end of the article
}

MDs [3]. Okubadejo and his colleagues stated that the prevalence of all categories of movement disorders was $28.0 \%$ [4]. They found that the prevalence rate of primary and secondary dystonia together to be (14.7\%), and the prevalence rate of chorea to be $(<1 \%)$. Their study was a hospital-based study in Nigeria and included $184 \mathrm{MDs}$ patients with movement disorders.

Dystonia is a movement disorder that causes sustained muscle contractions, repetitive twisting movements, and abnormal postures of the trunk, neck, face, arms, and legs [5]. The prevalence rate per 100,000 population of primary torsion dystonia is 33 [3]. In their hospital-based study in Nigeria, Okubadejo and his colleagues reported that focal dystonia represents $81.5 \%$, generalized dystonia represents $11.1 \%$, and segmental dystonia represents $7.4 \%$ of all of dystonia cases. The most common dystonias were focal hand dystonia (29.6\%) and blepharospasm with orofacial dystonia (18.5\%) [4].

"Chorea" is a borrowed Latin word that was derived from the Greek (khoreia) that means a choral dance. 
The term Athetosis comes from the Greek word athetos, which means not fixed. It is a slow form of Chorea.

Because of the slowness, the movements have a writhing (i.e., squirming, twisting, or snakelike) appearance [6, 7]. Wenning and his colleagues stated that the prevalence rate of chorea and athetosis was $<1 \%$ of all movement disorders that were found in their Bruneck study [2].

The aim of this study is to estimate the prevalence of dystonia, chorea, and athetosis in Al Quseir City, Red Sea Governorate (Egypt) as a part of a big project studying the epidemiology of many neurological disorders through door-to-door survey.

\section{Subjects and methods}

The present work is a population-based door-to-door (including every door) study among the population of $\mathrm{Al}$ Qusier City, Red Sea Governorate, Egypt. The sampling unit was all persons, of nuclear families or extended families, at any age in a door-to-door survey. The study area, $\mathrm{Al}$ Quseir City was a representative of cities lying on Red Sea [8]. The total screened population in Al Qusier City was 33, 818 subjects, while $1.6 \%(N=533)$ refused to participate in the study due to different causes. Subjects were reached at their locations if they were not at their homes at the time of first visit; they were revisited at the next time.

\section{Methods}

This study was conducted through three stages including

Phase I (screening phase): data collection was performed by three qualified neurologists, through a standardized screening questionnaire [9] to pick up any suspected cases of dystonia, chorea, and athetosis.

Phase II (diagnostic phase): in phase II, all subjects who were suspected to have dystonia, chorea, and athetosis were invited to attend at Al Qusier General Hospital where they were fully evaluated by three specialists of neurology each one separately. All data for each patient was registered in a specialized sheet prepared specifically for this study.

Phase III (investigatory phase): any investigations needed were done for the patients to diagnose dystonia, chorea, and athetosis.

\section{Statistical analysis}

Data analysis was carried out by using SPSS version 16 (SPSS Inc., Chicago, IL, USA), Excel (Microsoft Corporation, Redmond, WA, USA), and EpiCalc 2000 (Microsoft Corporation, Redmond, WA, USA). In fact, in this study, we just used descriptive parameters (like number and percent), as it is a simple epidemiological study of a unified design.

\section{Results}

A total of 33,285 subjects were screened out of the total population in $\mathrm{Al}$ Quseir City, and the prevalence of dystonia, chorea, and athetosis, were illustrated in Table 1. Dystonia was identified in 13 patients with a total prevalence of 39/100,000. Primary type was described in 3 cases with prevalence rate was 9/100,000 while 10 cases had secondary type either due to cerebral palsy ( 9 patients, with prevalence rate of $27 / 100,000)$ or post-encephalitic (one patient, with prevalence rate of $3 / 100,000$ ). Seven patients with chorea were identified with a prevalence of 21/ 100,000 . Rheumatic chorea was reported in 3 cases (prevalence rate of $9 / 100,000)$ and 4 patients had chorea due to cerebral palsy (prevalence rate of $12 / 100,000$ ). Athetosis was diagnosed in 5 patients (prevalence of 15/100,000). Cerebral palsy is an etiology of athetosis was encountered in 4 cases (prevalence rate of $12 / 100,000$ ) while 1 patient has post-encephalitic etiology (prevalence rate of 3/100, 000). Cerebral palsy was the most common cause of all types of studied disorders.

Table 2 showed the sex distribution of all recorded disorders. Only 2 patients have focal dystonia and 11 patients have generalized dystonia. Regarding anatomical classification of

Table 1 Prevalence and etiology of dystonia, chorea, and athetosis among studied population per 100,000 in Al Quseir City, Egypt

\begin{tabular}{llll}
\hline Extrapyramidal disorders & Etiology & Number of cases & Prevalence rate per 100,000 \\
\hline Chorea & Total & 7 & 21 \\
& Cerebral palsy & 4 & 12 \\
Dystonia & Rheumatic & 3 & 9 \\
& Total & 13 & 39 \\
& Primary & 3 & 9 \\
& Secondary: & & 27 \\
Athetosis & Cerebral palsy & 9 & 3 \\
& Post-encephalitic & 1 & 15 \\
\hline
\end{tabular}


Table 2 Percent of dystonia, chorea, and athetosis among both sex in Al Quseir City, Egypt

\begin{tabular}{llll}
\hline Extrapyramidal disorders & $\begin{array}{l}\text { Male } \\
\text { No (\%) }\end{array}$ & $\begin{array}{l}\text { Female } \\
\text { No }(\%)\end{array}$ & $\begin{array}{l}\text { Total } \\
\text { No }(\%)\end{array}$ \\
\hline $\begin{array}{llll}\text { Chorea }(\mathrm{no}=7) \\
\text { Cerebral palsy }\end{array}$ & $3(42.8)$ & $1(14.2)$ & $4(57.2)$ \\
Rheumatic & $3(42.8$ & $0(0)$ & $3(42.8)$ \\
$\begin{array}{l}\text { Dystonia (no = 13) } \\
\text { Primary }\end{array}$ & $1(7.7)$ & $2(15.4)$ & $3(23)$ \\
$\quad$ Cerebral palsy & $9(69.3)$ & $0(0)$ & $9(69.3)$ \\
Post-encephalitic & $0(0)$ & $1(7.7)$ & $1(7.7)$ \\
Athetosis (no =5) & & & \\
Cerebral palsy & $3(60)$ & $1(20)$ & $4(80)$ \\
Post-encephalitic & $0(0)$ & $1(20)$ & $1(20)$ \\
\hline
\end{tabular}

No number

cases of dystonia, we found that 12 cases with head and neck affection, 11 cases with upper limb affection, 11 cases with lower limb affection, and 11 cases with trunk affection. Taking into consideration that two-thirds of cases of dystonia are attributed to cerebral palsy.

\section{Discussion}

Diagnosis of extrapyramidal disorders is mainly a clinical one $[10,11]$. The number of existing cases of primary dystonia in the population is not precisely known, but the condition is probably much more frequent than reported.

This study examined the prevalence of three extrapyramidal diseases (dystonia, chorea, and athetosis) among the whole population (33,285 persons) in Al Qusier City, Red Sea Governorate, Egypt. The prevalence of dystonia in this study is $39 / 100,000$ while the result reported by El-Tallawy and his colleagues in Al Kharga District, Egypt, was (30.36/ $100,000)[9]$. This may be attributed to different environmental factors between east and west deserts in Egypt (mines are more common in east desert area including Al Quseir City). In our study, the most common focal dystonias were blepharospasm (56.4\%), cervical dystonia (36.7\%), limb dystonia (3.4\%), oromandibular dystonia (2.9\%) and laryngeal dystonia $(0.6 \%)$. Males with primary dystonia were found to have an earlier age of onset. We assume that such finding may be attributed to the fact that exposure of males to all environmental factors is more than females especially when they start working outdoors early in their lives. A female predominance was noted for most of the primary dystonia, with men to women ratio (M:F) of 1:2.01.

Moreover, the prevalence of primary dystonia $(9 / 100,000)$ is consistent with the results reported by Kandil who reported a prevalence of primary dystonia of 10/100,000 in Egypt [12]. A total of 1993 patients with movement disorders, were assessed in Bangkok, Thailand, dystonia was diagnosed in $8.4 \%$ of them [13]. On the other hand, the prevalence of primary dystonia in the current study is slightly lower than that reported by Defazio in Ashkenazi Jews. He found the prevalence of dystonia to be 11.1/100, 000, which might be attributed to racial, and genetic factors as the Jewish community is closed [14].

In our study, seven patients of chorea were identified with total prevalence of $21 / 100,000$. When taking in consideration etiology of chorea, cerebral palsy is the most common cause of chorea in our study as its prevalence is $12 / 100,000$ which appears more prevalent than that of a study conducted in Saudi Arabia by Rajeh [15] who reported a prevalence of 5.3/100,000. This difference may be attributed to lack of perinatal care measures in $\mathrm{Al}$ Quseir City and also due to changes in socioeconomic level between the populations involved in the studies.

In our study, rheumatic chorea is the second most common cause of chorea $(9 / 100,000)$. This is in agreement with that in case series from Tunisia, Brazil, and Turkey [16-18] that reported rheumatic chorea to be the commonest form of acquired chorea and it occurs in approximately one-third of children suffering from rheumatic fever. Actually, the prevalence of rheumatic chorea in $\mathrm{Al}$ Quseir City was comparable to that in Turkey $(14 / 100,000)$ [19], Hawaii, USA (7/ $100,000)$ [20], and it looks lower than rates in India (18.8/ $100,000)[21]$. Comparing it with other studies in Egypt, it is quite similar to that recorded by Eltallawy [9] in Alkharga District, Egypt $(8 / 100,000)$ and far lower than that recorded in Assiut, Egypt by Kandil [12] (62/100,000). This decrement in prevalence is consistent with international records that rheumatic chorea prevalence is decreasing mostly due to major advancement in antibiotic era and eradication of infections which is a major cause of the disease. In our study, age distribution shows that all patients of rheumatic chorea are children in school age (5 years, 6 years, and 9 years), it is consistent with the India study in which it was reported that all cases of their study are in school age with mean 9.4 years [21].

In this study, the prevalence of Athetosis was 15/100,000. This figure is comparable with results of Kandil [12] in Egypt who reported a prevalence of $12 / 100,000$, but more than that stated by Tekle [22] in Ethiopia $(5 / 100,000)$, and El-Tallawy [9] in Al Kharga District, Egypt $(1.6 / 100,000)$. High prevalence of Athetosis in our study could be explained on etiological basis as all reported cases of athetosis were secondary type (one case has post-encephalitic etiology and four cases are due to cerebral palsy mixed type).

\section{Acknowledgements}

Not applicable.

\section{Authors' contributions}

RB and MAE carried out this work and wrote the manuscript. MAMS designed the study and had done the statistical analysis. AE and MM did the literature search and coordinated the research team. All authors were involved in drafting the article or revising it critically for important intellectual content, and all authors read and approved the final version to be published. 


\section{Funding}

There is no source of funding for the research.

\section{Availability of data and materials}

Supporting results of this article are included in the article.

\section{Ethics approval and consent to participate}

A written consent was taken from all of the participants after explaining the details, benefits as well as risks to them. The study was approved from the institutional ethics committee of Faculty of Medicine, Assiut University, under the number of R0179N2015 at 19th of June 2015.

\section{Consent for publication}

Not applicable.

\section{Competing interests}

The authors declare that they have no competing interests.

\section{Disclosure of conflict of interest}

All authors assure that there is no conflict of interest. All used resources are supported by Assiut University.

\section{Author details}

${ }^{1}$ Department of Neurology and Psychiatry, Assiut University, Postbox: 71526 ,

Assiut, Egypt. ${ }^{2}$ Department of Neurology, Sohag University, Sohag, Egypt.

${ }^{3}$ Department of Neurology, Aswan University, Tingar, Egypt.

Received: 15 December 2018 Accepted: 21 August 2019

Published online: 02 September 2019

\section{References}

1. Mink JW. The basal ganglia and involuntary movements impaired inhibition of competing motor patterns. Arch Neurol. 2003;60(10):1365-8.

2. Wenning GK, Kiechl S, Seppi K, Müller J, Högl B, Saletu M, Rungger G, Gasperi A, Willeit J. Prevalence of movement disorders in men and women aged 50-89 years (Bruneck study cohort): a population-based study. Lancet Neurol. 2005:4(12):815-20.

3. Fahn S, Jankovic J. Principles and practice of movement disorder. 1st ed; 2007.

4. Okubadejo NU, Ojo OO, Oshinaike OO, Bankole IA, Aiyejusunle CB. Spectrum of movement disorders at the premier Lagos movement disorders clinic in Nigeria: first year's experience. Mov Disord. 2012;27(Suppl 1):16.

5. Fahn S, Bressman SB, Marsden CD. Classification of dystonia. Adv Neurol. 1998;78:1-10.

6. Berman SA. Chorea. In: Joseph AB, Young RR, editors. Movement disorders in neurology and neuropsychiatry. 2nd ed. Malden: Blackwell Science; 1999. p. 481-94.

7. Dorland WA, editor. Dorlands illustrated medical dictionary. 30th ed. Philadelphia: WB Saunders; 2003.

8. Saed M. Gaber, Samia M. Aly and Karim A. Masood, (2010) Center of information and decision on making, Red Sea Governorate achievement index. (In Arabic).

9. El-Tallawy HN, Farghaly WM, Metwaly NA, Rageh TA, Shehata GA, Elfetoh NA, Hegazy AM, El-Moselhy EA, Rayan I, Al-Fawal BM, AE MA. Door-to-door survey of major neurological disorders in Al Kharga district, new valley, Egypt: methodological aspects. Neuroepidemiology. 2010;35:185-90.

10. Hely M, Morris J, Reid W, Trafficante R. Sydney multicenter study of Parkinson's disease: non-L-dopa-responsive problems dominate at 15 years. Mov Disord. 2005;20(2):190-9.

11. Defazio G. The epidemiology of primary dystonia: current evidence and perspectives. Eur J Neurol. 2010;17(Suppl 1):9-14.

12. Kandil MR, Tohamy SA, Fattah HA, Ahmed HN, Farwiez HM. Prevalence of chorea, dystonia and athetosis in Assiut, Egypt: a clinical and epidemiological study. Neuroepidemiology. 1994;13:202-10.

13. Bhidayasiri R1, Kaewwilai L, Wannachai N, Brenden N, Truong DD, Devahastin R. Prevalence and diagnostic challenge of dystonia in Thailand: a service-based study in a tertiary university referral centre. Parkinsonism Relat Disord. 2011;17(Suppl 1):S15-9.

14. Defazio G, Abbruzzese G, Livrea P, Berardelli A. Epidemiology of primary dystonia. Lancet Neurol. 2004:3(11):673-8.

15. Rajeh SA, Bademosi O, Ismail H, Awada A, Dawodu A, Al-Frehei H, et al. A community survey of neurological disorders in Saudi Arabia: the Thugbah study. Neuroepidemiology. 1993;3:164-78.
16. Demiroren K, Yavuz H, Cam L, Oran B, Karaaslan S, Demiroren S. Sydenham's chorea: a clinical follow-up of 65 patients. J Child Neurol. 2007:22:550-4

17. Ben Hamida M, Hamza F. Sydenham's chorea in Tunisia: a report on 65 cases. Ann Med Interne (Paris). 1979;130(6-7):359-64.

18. Tumas V, Caldas CT, Santos AC, Nobre A, Fernandes RMF. Sydenham's chorea: clinical observations from a Brazilian movement disorder clinic. Parkinsonism Relat Disord. 2007;13(5):276-83.

19. Jamal M, Abbas KA. Clinical profile of acute rheumatic fever in children. J Trop Pediatr. 1989;35:10-3.

20. Chun L, Reddy D, Yim G, Yamamoto L. Acute rheumatic fever in Hawaii: 1966 to 1988. Hawaii Med J. 1992:51:206-11.

21. Ravisha M, Tullu J, Kamat J. Rheumatic fever and rheumatic heart disease: a clinical profile in 550 cases in India. Arch Med Res. 2003;34:382-7.

22. Tekle H, Abebe M, Gebre M, Forsgren L, Heijbel J, Holmgren G, et al. Community-based study of neurological disorder in rural central Ethiopia. Neuroepidemiology. 1990;5:263-77.

\section{Publisher's Note}

Springer Nature remains neutral with regard to jurisdictional claims in published maps and institutional affiliations.

\section{Submit your manuscript to a SpringerOpen ${ }^{\circ}$ journal and benefit from:}

- Convenient online submission

- Rigorous peer review

- Open access: articles freely available online

- High visibility within the field

- Retaining the copyright to your article

Submit your next manuscript at $\boldsymbol{\nabla}$ springeropen.com 